\title{
View of Mexican family members on the autonomy of adolescents and adults with intellectual disability
}

\author{
Betania Allen-Leigh, PhD, (1) Gregorio Katz, MD, (2) \\ Guillermina Rangel-Eudave, BS in Psych, (2) Eduardo Lazcano-Ponce, MD, ScD. (1)
}

\section{Allen-Leigh B, Katz G, Rangel-Eudave G, Lazcano-Ponce E. View of Mexican family members on the autonomy of adolescents and adults with intellectual disability. Salud Publica Mex 2008;50 suppl 2:S2I3-S22I.}

\begin{abstract}
This study aims to describe the ways in which Mexican adolescents and adults with intellectual disability exercise autonomy. Two focus groups were carried out with family members who are the legal guardians of people with intellectual disability who have received independent living training at the Center for Integral Training and Development (CADI, per its abbreviation in Spansh). Focus group transcripts were analyzed with codes defined a priori, based on an existing theoretical framework on autonomy and quality of life among intellectually disabled persons. Autonomy is exercised by the intellectually disabled in the personal, social, sexual and economic spheres of life. Empowered autonomy implies that the person is taught the necessary skills and then allowed to act upon his or her own interests. Negotiated autonomy includes guidance, explanation and negotiation; it constitutes a learning process. Interpreted autonomy is the most limited type described, and implies protection, interpretation and may involve decision-making by others. These types of autonomy constitute a complex phenomenon and the divisions between them are indistinct.
\end{abstract}

Key words: intellectual disability; autonomy; empowerment; qualitative research methods; Mexico
Allen-Leigh B, Katz G, Rangel-Eudave G, Lazcano-Ponce E. Puntos de vista de familiares de adolescentes y adultos mexicanos con discapacidad intelectual acerca de su autonomía. Salud Publica Mex 2008;50 supl 2:S2I3-S22I.

\section{Resumen}

Este estudio busca describir las maneras en que jóvenes y adultos mexicanos con discapacidad intelectual ejercen la autonomía. Dos grupos focales se llevaron a cabo con familiares de personas con discapacidad intelectual quienes han recibido capacitación para la vida independiente en el Centro de Capacitación y Desarrollo Integral, CADI. Se analizaron las transcripciones con códigos definidos a priori, basados en un marco teórico preexistente sobre autonomía y calidad de vida entre personas con discapacidad intelectual. Las personas con discapacidad intelectual ejercen autonomía en diversos ámbitos: personal, social, sexual y económico. La autonomía empoderada se da cuando se le enseña a la persona las habilidades necesarias y luego se le permite actuar con base en sus propios intereses. La autonomía negociada implica ser guiado en las acciones, recibir explicaciones y negociar las decisiones; constituye un proceso de aprendizaje. La autonomía interpretada es el tipo más limitado que se describe, e implica protección, interpretación y puede involucrar la toma de decisiones por otros. Estos tipos de autonomía constituyen un fenómeno complejo y las divisiones entre ellas son difusas.

Palabras clave: discapacidad intelectual; autonomía; empoderamiento; métodos cualitativos de investigación; México

(I) Centro de Investigaciones en Salud Poblacional, Instituto Nacional de Salud Pública.

(2) Capacitación y Desarrollo Integral AC. Universidad Nacional Autónoma de México.

Address reprint requests to: Betania Allen-Leigh. Dirección de Salud Reproductiva, Centro de Investigaciones en Salud Poblacional,

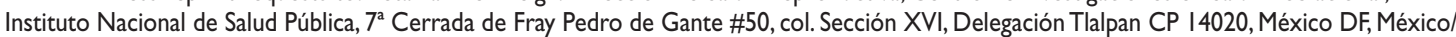
Gregorio Katz. CADI. Hidalgo 7, col. Granjas de Guadalupe, Cuautitlán Izcalli, Estado de México, 54700 México. E-mail: ballen@insp.mx, gkatzmina@prodigy.net.mx 


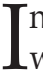
most parts of the world social services for people with intellectual disability focus increasingly on social integration ${ }^{1-3}$ and autonomy in various spheres of life. ${ }^{4,5}$ Most notably in high-income countries (European nations, the United States, Canada, Australia) but also in middle-income nations such as China and Mexico, recent policy in the field of intellectual disability has emphasized social integration. ${ }^{1,2,6-11}$ Issues that must be dealt with when promoting integration of people with intellectual disabilities into the community and their inclusion in employment are training in vocational and applied (practical) living skills and supported living services or structures for assisting independent living. These issues are closely related to autonomy, and constitute, in essence, the practical building blocks of autonomy for people with intellectual disabilities.

Autonomy is an important element of quality of life for all persons, including the intellectually disabled. ${ }^{12,13}$ What autonomy means and its importance for people with intellectual disability and their families (especially their parents), the role it plays in quality of life, how people with intellectual disability exercise autonomy and how to support and facilitate its development are current topics of interest and research. ${ }^{4-7,14,15}$ However, little research has been done on how autonomy in the context of intellectual disability is understood, implemented or supported in Latin America, Africa and most of Asia.

Autonomy can be understood as a process within which an individual develops his or her own opinions and values, makes decisions and choices, and carries out actions based on these values and personal tastes, in the context of social interaction with others. Exercising autonomy can include a learning process in which values, needs and tastes are developed; learning can be acquired through practical experience in exerting control over decisions or through interaction and negotiation with others. Autonomy can also be interpreted by others, and the person attempting to exercise his or her autonomy can either cooperate with the interpretation or resist it, through challenging or other behaviors. ${ }^{14,16}$

In the present article this concept of autonomy is applied to qualitative data collected from family members (legal guardians) of adolescents and adults with different levels of intellectual disability in Mexico. All of the intellectually disabled family members in question attend or have graduated from a training program for independent living that promotes autonomy in people with intellectual disability (the program offered by the Center for Integral Training and Development, CADI for its initials in Spanish, http:/ / www.cadi.org.mx/; see also the article by Katz et al. in this volume). This exploratory qualitative study describes the spheres of life in which Mexican adolescents and adults with intellectual disability exercise autonomy (after receiving at least some degree of training in independent living) and the gradients of autonomy that are developed in the relationship between them and their parents or family members who are their legal guardians, from the perspective of these caretakers.

\section{Material and Methods}

As part of a larger study on quality of life of people with intellectual disability after having received training in independent living, qualitative research methods were used to explore autonomy as an important domain of quality of life. The analysis herein presented is based on two focus groups with legal guardians of clients of the CADI, a non-profit, non-governmental organization which provides training and support for independent living and social inclusion of adolescents and adults with intellectual disability in central Mexico.

Participants in the focus groups included mainly parents, but also sisters, brothers and one grandparent of current or former CADI clients. The intellectually disabled family members referred to in group interviews were between 17 and 30 years of age and had received between two months and eight years of training in independent living. Staff interviews were also carried out, and other aspects of quality of life were analyzed (especially social inclusion) but are not included in this report. ${ }^{17,18}$

Legal guardians of current and former CADI clients were contacted by phone and invited to participate in the focus groups, which were held at CADI. A female moderator with experience in focus group methodology who is not employed at CADI explained the objective of the research -to explore how their family member's quality of life had been affected by training received at CADI-, emphasizing that participation was voluntary and that refusal to participate would not affect their family member in any way. Those invited family members who agreed to participate provided verbal informed consent, which was taped, as was the rest of the interview. Taped focus groups were transcribed verbatim (in Spanish).

This qualitative analysis aimed to gain insight into parents' and other caretakers' perceptions of the ways in which their family member with intellectual disability exercises autonomy after having received various degrees of independent living training (depending on time in the training program and level of disability). We analyzed the focus group transcripts using the constant comparative method recommended by the authors of 
grounded theory, repeatedly reviewing the text. ${ }^{19} \mathrm{How}-$ ever, the categories applied did not emerge from the data; that is, in vivo codes, typical of grounded theory studies, were not used. Instead categories based on a pre-existing theoretical framework (a priori codes) were used ${ }^{20}$ taken principally from van Hooren et al. 2002 (categories relating to autonomy) and Bramston et al. 2005 and Bertelli and Brown 2006 (categories pertaining to other aspects of quality of life)..$^{14,21,22}$ Focus groups were analyzed in Spanish and selected quotations were translated into English for inclusion in this report. Quotations that appear below are followed by FG1 for focus group 1 and FG2 for focus group 2; names and other details have been changed to maintain confidentiality.

\section{Results and Discussion}

In this study, autonomy is defined as a process that occurs in a social context. This means that in the specific case studied here, it is developed through interaction between people with intellectual disability and others. Autonomy is exercised in different spheres of life and to different degrees. When people exercise empowered autonomy they carry out actions or make choices based on their own tastes, opinions and values, and learn by doing, through the practical implementation of their autonomy. People may also negotiate their autonomy with caretakers (parents, other family members, service providers), and this can be a learning process in which they acquire knowledge about their best interests or about how to make choices or take action in a way that is not harmful to themselves. However, a person's autonomy may also be interpreted by others, implying that the intellectually disabled person's tastes or desires are represented or translated by their caretakers. This situation may be deemed necessary to preserve the wellbeing of the person in question. However, it generally excludes the possibility of the person learning about his or her own best interests or how to go about obtaining them in a safe and socially acceptable way, given that it implies not only interpretation of the person's wishes but also cooperation with or submission to this interpretation. ${ }^{14}$

This way of conceiving autonomy implies that it is not a dichotomous concept; that is, it is not simply a question of whether or not autonomy is exerted, but how each individual gradually develops a sense of what his or her own best interests are, learns how to decide on the best course of action and then how to carry it out. This more complex way of defining autonomy involves not only freedom of choice and self-determination but also self-understanding, self-development and self-realization. This definition of the concept of autonomy, which is used in our analysis, is based on the excellent work by van Hooren et al., on development of autonomy in people with Prader-Willi syndrome. ${ }^{14,23,24}$

\section{Spheres of autonomy}

Autonomy is exercised in different spheres of life, including in personal terms (control over one's life and body, including at a practical, day-to-day level, for example, dressing oneself, caring for one's personal hygiene, deciding what one will eat, etc.), social terms (choosing friends and other types of social relations, deciding when, how and with whom to socialize), with relation to sexuality (deciding when, what type and with whom to have erotic interaction) and in economic terms (earning a salary and managing one's own funds). ${ }^{14,25,26}$

Exercising personal autonomy includes practical aspects of existence, including carrying out activities related to personal hygiene, dressing oneself or going to the bathroom alone, deciding what one will eat and in general having control of and making decisions about one's person and body. ${ }^{4,14,27}$ Some examples of personal autonomy described by parents of Mexicans with intellectual disabilities follow:

Mother: We are no longer looking over his shoulder [all the time]. He prepares his bath even if he's alone, and formerly we did everything for him, everything. Now he demands independence, saying "allow me, I am going to decide what I am going to have for supper and I am going to prepare it." (FG1)

Mother: So, my son has learned to be more independent, although his grandmother coddles him, spoils him. But my son has learned to care for his personal hygiene alone, he bathes, he prepares his clothes, he gets dressed, he arranges his room. If he sees that I'm busy, he doesn't interrupt me, or if he's hungry, he goes to the kitchen and he heats up his food. (FG2)

Mother: My son is an independent kid. He washes his clothes. If he's hungry, he prepares food for himself. (FG2)

In these quotes, the three mothers describe the way in which, after undergoing independent living training at CADI, their sons bathe alone, get dressed by themselves, prepare their own meals, pick up after themselves and wash clothes. Here is another example of personal autonomy, in the context of a more severe intellectual disability: 
Brother: Although she has many limitations, whenever we take her [to spend time with family members], she makes an effort to carry out basic tasks. When she finishes eating, she takes her plate to the kitchen and tries to wash it. She makes her bed. She tries to brush her teeth, to wash herself. (FG2)

Social autonomy includes choosing friends, deciding what to do with friends and family and when to see them, selecting which social gathering places (in modern society, restaurants, stores, movie theaters, parks, etc.) to go to and when to go. ${ }^{4,5,28}$ The following is a very illustrative quote from one of the focus groups about the development of social autonomy in the son of a participating mother.

Mother: He has learned to defend himself and to say what he wants, and he tells us, for example, when there is a conflict between mom and dad, or between Ricardo, dad and mom. He says to us, "I don't agree with what you are saying to me." He has also learned to choose his friends more. Now he can distinguish between who is his friend and who isn't. There was a time when they took advantage of him. Once a person he thought was his friend hurt him, and later he told me, "He isn't my friend because he made me feel bad." I am pleased to see that he knows how to tell the difference and that ... he doesn't remain silent. That he decides if he doesn't want to go someplace. He has learned to decide for himself. Now with what's in style -he's 16 years old- he dresses very modern. Before when he had friends who were girls, he always thought they were his girlfriends, and now he can tell the difference, if they are friends or if one is his girlfriend. For example, he has also learned to distinguish what type of clothes should be used at a certain time, if he should wear a suit and tie or shorts. Because one day we were going to dinner, and when I went to his room he had the suit ready. I was pleased, because he has learned that here [at CADI]. (FG2)

The young man the mother describes exercises his autonomy during social interactions with his parents (participating in discussions, voicing his opinion), by choosing who his friends are based on his own best interests, deciding where to go and in issues related to social norms such as how to dress.

Sexual autonomy, which may be considered a subset of social autonomy, includes choosing with whom, when and how erotic interaction with others will occur. ${ }^{29,30}$ There were very few comments by parents about sexual autonomy and they focused solely on the existence of romantic (boyfriend-girlfriend) relationships. In part this is due to the fact that the focus group guide did not deal specifically with this aspect of autonomy, but it may also indicate that sexual autonomy is an area which parents of people with intellectual disability find especially difficult.

Mother 1: Because they also have boyfriends and girlfriends...

Moderator: It seems like many have boyfriends and girlfriends, right?

Mother 2: Well yes, but it's their age. (FG1)

Mother: Yes, my daughter has said to me that she has a boyfriend, and then that another asked her out. But I do have to teach her the social norms, that is, that she can't have various boyfriends at the same time. (FG1)

Mother: He has a girlfriend here [at the residence in $\mathrm{CADI}$ and he asks her to go out with him; they give her permission to go out [with him]. (FG1)

Economic autonomy implies exercising control over the economic aspects of one's own life, including earning a salary, deciding what to spend money on and managing a budget. ${ }^{4,14}$ In the focus groups, caretakers described the importance of economic autonomy for their family members with intellectual disability, and what exactly it consists of.

Mother: Also a part of our expectations is that at some point in time they be able to carry out a technical activity, at the level each kid can handle, but that will be a way to make a living, with an income, and that at some point in time they be able to count their money, to know, "how much did I spend, how much do I have left." (FG1)

Mother: Right now they are working in carpentry... $\mathrm{He}^{\prime}$ s happy because he gets a salary. He administers it. (FG1)

Father: I think it is very useful [vocational training], because they learn a discipline, that they have to go [to work] and they have to fulfill expectations, and in addition there is a payment. Not much, but for them it is interesting to receive an envelope with eighty pesos for their week of work. (FG1)

According to these parents, and other family members who commented on this aspect of autonomy, important elements of economic self-determination include supporting oneself by earning a salary, managing a personal budget and deciding what to spend money on. A sense of responsibility and a sense of achievement are also important issues developed in the context of integration of people with intellectual disability into 
paid employment, and were mentioned repeatedly in both focus groups.

\section{Gradients on the autonomy continuum}

According to the definition of autonomy used in the analysis, it constitutes a process that takes place in the context of social interaction; that is, when autonomy is exercised, this does not occur in a social vacuum. If a person with intellectual disability is not impeded in exercising his or her autonomy, but first provided with skills necessary for acting upon and pursing their own interests and then not prevented from pursuing his or her goals, this is termed empowered autonomy. Thus, empowered autonomy implies the full implementation of autonomy, self-determination, choice and self-directed action, but even in this case it takes place in the context of social relationships. ${ }^{14,23,24}$

For people with intellectual disability, exercising autonomy (becoming empowered) can often begin with what can seem to be very insignificant or minimal objectives, such as going to the bathroom alone, dressing and bathing oneself, caring for other aspects of personal hygiene and for one's clothing or deciding what to eat. However, these are important goals, albeit things that many of us take for granted. . $3,14,21,22$ A number of focus group participants described the way in which their family member with intellectual disability exercises empowered autonomy, often emphasizing the growth that has taken place as a result of receiving training for independent living. They mentioned both smaller and larger decisions that their family member made and different types of opinions, tastes, values and goals they acted upon.

Mother: Well, my son defends himself now. He chooses his clothes and what sort of things he wants ... If he doesn't like someone, he says so. It can be uncomfortable, but he decides who's his friend and who isn't. It's good that he chooses his clothes, his shoes or the way he wants to dress. This is progress, that he defends himself from me or from his cousins, although he spoils them, but if they hit his brother, he defends him. He's not used to that. He has a response to aggression, he is aware that aggression isn't good. He has a television, watches his programs and listens to the radio. Then when I say to him, "Hey, let me watch your TV," he says, "No, watch yours." I like that he defends himself, that he sets limits. (FG2)

Mother: I have a hope that my son can become independent, that he can make his own way. That he can know that life isn't just being with mommy or in little schools.
No, we arrived at a different place [CADI], a place where there is a real program designed to make them independent, productive and most of all happy. (FG1)

Sister: Well, as for my sister, my parents overprotected her a lot. And something that surprised us, it was incredible, is that one day she went out, and she traveled to Puebla [a different city where her family lives] by herself. That level of self-sufficiency! ... So as I was saying about my sister, that she went to Puebla alone, and knew how to get there. And she even got home and my dad wasn't there and she went over to a neighbor's, and she even said to him, "don't tell my sister because she is going to scold me" [laughs]... She arrived in town and took a taxi from the bus station to get home. (FG2)

The empowered autonomy described by family members ranges from choosing what to wear or what to watch on television, to traveling alone, living independently in larger society and rejecting violence as an acceptable part of social interaction.

Negotiated autonomy is exercised with influence from others, through discussion and compromise. It often involves a learning process in which people attempting to exercise their autonomy get a clearer idea of their own needs and interests, and at times reformulate their own values, as when they understand that their desire may conflict with their own best interests. ${ }^{14,24}$ In order to constitute what we classify as negotiated autonomy, and to allow learning to occur, the social interaction around the attempt to exercise autonomy must include negotiation and discussion or at least explanation of the reasons why a certain choice or action might be harmful (otherwise, an option is being imposed, not negotiated). Learning occurs when people understand the conflict between their tastes or desires and their own, often longer-term, interests. ${ }^{14}$ Four mothers (more mothers participated in the focus groups than any other type of family member), describe the way in which their children exercise negotiated autonomy:

Mother: Lately he has said, "Mom, money", that he wants to work. He is in one of the levels here [at CADI], the groups. I think David is in the second or third level. So he would like to work, and I said to him, "Well, yes, but you have to work hard, you have to obey, you have to be good so you can get to a higher level and earn money," I said, "Otherwise you can't get a job." (FG1)

Mother: He has his moments too. He saw a couple and started, “Mom, I don't, mwa, mwa" [sound of kissing, laughter from the group]. I said to him, "No son, no son, right now there is no girl." And he said, "Hmmm"... 
Mother: For example, my daughter is fascinated by the idea of being noticed physically. So she wants to wear red lipstick and eye shadow on her eyes [mimes applying a lot of eye shadow] and her hair like Rarotonga [sexy female comic book character with a large afro]. So I have to work with her a lot. I am not going to tell her how to dress, but I will tell her not to use so much makeup. Also, she has a great body and is very attractive; she doesn't like pants. Fortunately she likes long skirts. (FG1)

Mother: We say to him, son, we are going to such and such a place, and he remembers that we had to walk a lot, and he says "No, I'm not going." I explain to him, son, you can't stay home [alone]. Then we go shopping, and he chooses his CDs, I explain that he can buy one, but he decides. (FG2)

In these narratives, the mothers do not say to their children, "you cannot do this or that". Instead, they say things like, "You have to study hard, learn to work, and then get a job". They explain things to their children and negotiate with them. For example, saying "I have to work with her a lot," implies the mother does not simply impose rules about how much makeup to wear, but instead discusses the topic with her daughter and guides her in making choices about this (and in addition, she does not tell her how to dress). In the last quote, the mother explains both that for her son's own safety he cannot stay home alone, and also practical, external limitations (not all the family's money can be spent on CDs), and then allows him to exercise some autonomy by deciding which single $\mathrm{CD}$ to buy. Even when the disabled person has a limited capacity for communication, as appears to be the case in the first two quotes, autonomy can be negotiated.

Interpreted autonomy implies a situation in which the person's tastes or desires are interpreted by others, and their decisions and actions are guided by others, sometimes to the point of being imposed by others. It is often not clear how well the interpreted wish or opinion corresponds with the person's actual desire. There may be cooperation with or acceptance of the interpretation by others, but without an explicit indication of whether the person actually desired this or something else. Even if there appears to be resistance against the interpretation and guidance in the form of challenging behavior, it can be unclear whether this behavior is an attempt to communicate disagreement or is due to other issues. ${ }^{12}$ This is especially complex when the person's intellectual disability is more severe or when multiple disabilities make communication difficult. However, as defined here, interpreted autonomy does not explicitly involve discussion or explanation when guiding the person's actions; if that were the case, it would be pushed farther along the continuum of autonomy (over the fuzzy dividing lines between gradients) into negotiated autonomy. Because explanation and discussion do not come into play in this type of autonomy, there is little chance for learning to take place. Although a limitation of the person's autonomy may be present, the motivation for this tends to be providing better care or protecting the person. ${ }^{10,14,23-25}$

The narratives that follow provide examples of interpreted autonomy:

Mother: No, Alejandro isn't like that [a rebellious teenager], people also tell me he is neater than other kids and he behaves. But I think that maybe in a wedding with 500 people, he would see young people dance, and see young people drink, and if he is going to ask a girl he doesn't know how to dance, she's going to say no. It's just that, society isn't prepared yet, so you have to know where and with whom to take them. Neighbors treat him fine, in general people treat him fine, but you shouldn't expose him to rejection. For example, my son doesn't walk straight or speak clearly, and so people are going to say, "this guy is drunk". (FG1)

Mother: A schoolmate of mine said to me, "Look, why not, while you decide if she'll keep going to school, let her work at my drug store." She started working there. I knew it was going to be very difficult, because my daughter has problems counting money. I also thought that they were going to give her easy work to do, but they had her doing everything. Sometimes she handled money and I felt bad because I thought that the other employees could get her in trouble or even rob her or trick her. One day one of them said to my daughter, "You know what Inés? You're useless, you can't do anything." But my daughter has a strong personality and she gets mad ... One day she told me what had happened at work and I said to her, "You're not going to go back to work there, because you're this far from getting blamed for taking money and they could accuse you of something." My husband and I talked about it and came to that conclusion, because we don't want anyone to treat her badly.

In both of these narratives, the mothers are principally concerned with protecting their children from rejection, bullying and other types of mistreatment. However, in neither case do they describe explaining or negotiating the decision with their children. Instead, they interpret what their children want and need, and then either make the decision themselves (not take him to large social events where people do not know him) or inform their child of the decision taken by their parents (the daughter will no longer work at the drug store). The 
fact that it is entirely possible that these decisions are in the best interests of the son and daughter, and may coincide with their own wishes, illustrates the complexity of understanding and facilitating autonomy in the daily lives of people with intellectual disabilities.

Two other mothers describe the way they make decisions about the romantic or sexual autonomy of their daughters:

Mother: Before, Tania went to a normal school just for girls, and at that time I was recently widowed, and she couldn't stay there because of her age. So I said, what am I going to do? Thankfully, I received information about CADI, and I came, but I was worried because it was co-ed. And the doctor explained to me that they had a very efficient program to teach the guys and girls which behaviors are forbidden: I don't touch, I don't kiss... And my daughter has been fine here, she's been here 15 years. She is very well behaved and as a mother I have the confidence they are watching over and taking care of her. (FG1)

Mother: Well, for a time she did have a boyfriend here, a boy, but later I don't know what happened, you know? And she did miss him a lot... But now she is okay, very calm. Once, yes, the teacher asked me what was going on, if she wanted to get married, but I told him, "No, Virginia, for marriage, no. Her as a housewife, no." I said, "She likes to flirt around." (FG1)

As mentioned before, sexuality appears to be an issue that parents of people with intellectual disability find especially difficult (staff also commented in interviews that sexual and reproductive rights of the intellectually disabled are extremely complex issues), and this is indicated in the narratives. These two examples constitute examples of interpreted autonomy in that there is no specific indication that daughters agree with, or even that they have been informed of the decision against their having a boyfriend or getting married. Given that there is no discussion, there is no room for these daughters to learn about how to exercise autonomy or develop their own values and opinions related to this issue.

\section{Reactions to attempts to exercise autonomy by the intellectually disabled}

One reaction by parents towards attempts by their children with intellectual disability to exercise their autonomy is to relinquish control, allowing freedom of choice and action. ${ }^{10,31}$ In the case of the parents inter- viewed here, relinquishing control is facilitated by the fact that their children have received training for living independently at CADI. In addition, CADI provides family therapy oriented towards dealing with parental tendencies towards overprotection of their children with intellectual disability.

Mother 1: Yes, my daughter even wants to travel alone [to school], and that just can't be.

Mother 2: Well, my daughter does come here alone. Today I let her come because I knew I would arrive later.

Mother 3: For example, my daughter has ridden the bus. I have allowed her to do so. (FG1)

Mother: He's an only child; I'm an overprotective mother. I have had to change a lot of my attitudes towards him, because he, after coming here [to CADI for training] has demanded of me, has demanded that I leave him alone, that he has learned to make his own decisions, and not to choose from what I offer him: his clothes, his things, his TV shows. (FG1)

Father: For example, when we go to a store, he really likes to go look at the CDs and we let him go alone to ask about them. (FG1)

Mother: Maybe if I don't want to give him a knife at home to cut carrots with, and here [at CADI] he does it, well, that's part of his development.

Father: For example, with this lady, I would say to her: "If they teach him to use a knife here, let him use it at home." (FG1)

Mother: I don't have that problem; that he tries to become independent by being rebellious. Instead, I see his character now and he makes his decisions. He chooses what to eat. He doesn't speak much but he makes you understand him perfectly. (FG1)

Another possible reaction by parents towards their children with intellectual disability when they attempt to exercise their autonomy is to resist relinquishing control, or not want to hand over control, often implying overprotection. Since, as mentioned, families of CADI clients receive therapy to deal with overprotection of intellectually disabled family members, the following quotes tend to criticize this type of reaction.

Father: From my perspective, what I think is that we overprotect them. We want to do lots of things for them. Well, I'm speaking for myself, but we don't give them the opportunity to develop on their own. (FG2) 
Sister: She lives with my father and he's older and now they have different ways of getting along, so I really see changes. I don't know how independent she can be, because she lives at home on the weekends, so she's returning to the same environment, with my father and he, as an older person, well he has his routines, and so all of a sudden she arrives and is back in the same system. Moderator: She lives here [at CADI] during the week then, and goes home for the weekends?

Sister: That's right, she lives here during the week and leaves on the weekend, and well, there has been a change in her and also in my father, but it has been difficult for him. A change in mentality, because of the [independent living] program. For him the best thing would be if she were with him always, and it is difficult for him, but we're getting towards acceptance by him. (FG2)

Father: I think that's the key, that we take away our children's ability to do things. So one day they said to me, "Hey, why doesn't he come and go alone [to CADI]?" And I almost flipped. I don't think Enrique is capable; nevertheless, the teacher sees him as a person who can do it. Enrique is my roommate, really, he slept with me ... although he had his own room. And, well, I'm speaking for myself, right? But I see it clearly, you know? How I was ruining my son. There was someone who cooked for him, who took care of him, but not someone to teach him. Just being with him, but no structure and no socialization. (FG2)

Respecting autonomy implies acknowledging a person's right to have opinions, to make choices, and specifically, allowing them to take action based on his or her values. ${ }^{14,23-25}$ However, in the context of intellectual disability (and not only in this context), this issue can be complex. When children, adolescents and even adults with intellectual disability exercise their autonomy, parents, other family members who are legal guardians, and personnel who provide social and health services, may have difficulty relinquishing control. As with all children, and especially adolescents, parents may resist allowing them to exercise their autonomy without guidance, in an attempt to protect them from the negative consequences of their actions. This means that parents may have doubts as to whether the object of their children's desire is good for them or is in their best interests. In this situation, autonomy is negotiated between parents or other caretakers and the person cared for. This negotiation involves protecting the persons considered less competent so that they are not harmed in the short or the long term. ${ }^{14,23,24}$ Such harm could occur because persons are is acting on a desire or opinion that is not in their best interests (working at a certain job or spending all their money on one purchase) or because they are unable to carry out the intended action correctly and safely (using a knife to cut food or using public transportation).

The way this negotiation is carried out affects the process through which autonomy develops. Thus, if persons are taught the necessary skills and then allowed to freely exercise their autonomy with little or no intervention by others, what is termed empowered autonomy, there is a process of learning by doing or from experience. If autonomy is negotiated, with explanation from the parent or other caretaker about why a certain desired action or goal is not in the persons' best interests and discussion with them, they may learn through being taught. ${ }^{14}$ But, if autonomy is interpreted by the caretaker -that is, persons' interests are interpreted, paraphrased or translated by the caretaker- without discussion, this implies that they must cooperate or obey, or perhaps rebel and resist but usually without success, leaving little room for learning about their best interests or safe ways to exercise autonomy. ${ }^{14}$ When autonomy is interpreted, opinions and values tend to be defined by others and autonomy is limited, restricted or at times denied. However, the dividing lines between these types of autonomy are blurry; they constitute gradients of autonomy on a continuum, not completely distinct entities.

\section{Conclusions}

This qualitative analysis has attempted to show that, when applied to the lives of people with intellectual disability, the concept of autonomy is very complex, as is the reality of its implementation. We concluded that it is not a simple matter of limited versus full-fledged autonomy. There may be gradients of autonomy, but the dividing lines between them are indistinct. In addition, the reasons why caretakers (parents and other family members, service personnel) react in one way or another to the intellectually disabled person's attempt to exercise autonomy are important to understanding this social process.

This exploratory study constitutes a jumping-off point for future studies, by our research team and others, about intellectual disability in Mexico. Qualitative and quantitative research on quality of life and autonomy, adaptive and challenging behaviors, existing and needed policy and services and especially evaluations of the quality of public and private educational and social services should be carried out in the field of intellectual disability research in Mexico and other Latin American countries. Doing so will create a scientific foundation for promoting the wellbeing and protecting the rights of intellectually disabled citizens of these countries, and their families. 


\section{References}

I. Fillary R, Pernice R. Social inclusion in workplaces where people with intellectual disabilities are employed: Implications for supported employment professionals. Int J Rehabil Res 2006;29(I):3I-6. 2. Holt G, Costello H, Bouras N, Diareme S, Hillery J, Moss S, RodriguezBlazquez C, Salvador L, Tsiantis J,Weber G, Dimitrakaki C. BIOMEDMEROPE project: Service provision for adults with intellectual disability: A European comparison.J Intellect Disabil Res.2000;44 ( Pt 6):685-96. 3. O'Hara J. Standards and quality measures for services for people with intellectual disabilities. Curr Opin Psychiatry 2006; 19(5):497-50I. 4.Wehmeyer ML, Bolding N. Enhanced self-determination of adults with intellectual disability as an outcome of moving to community-based work or living environments.J Intellect Disabil Res 200I;45(Pt 5):37I-83.

5. Heller T, Miller AB, Factor A. Autonomy in residential facilities and community functioning of adults with mental retardation. Ment Retard 1999;37(6):449-57.

6. Young $L$. Community and cluster centre residential services for adults with intellectual disability: Long-term results from an Australian-matched sample.J Intellect Disabil Res 2006;50(Pt 6):419-3I.

7. Lifshitz H, Merrick J. Ageing and intellectual disability in Israel: a study to compare community residence with living at home. Health Soc Care Community 2003; I I (4):364-7 I.

8. Felce D, Emerson E. Living with support in a home in the community: Predictors of behavioral development and household and community activity. Ment Retard Dev Disabil Res Rev 2001;7(2):75-83.

9. Heller T, Miller AB, Hsieh K. Eight-year follow-up of the impact of environmental characteristics on well-being of adults with developmental disabilities. Ment Retard 2002;40(5):366-78.

10. Zhang D,Wehmeyr ML, Chen LJ. Parent and teacher engagement in fostering self-determination of students with disabilities:A comparison between the United States and the Republic of China. Remedial and Special Education 2005;26(I):55-64.

I I. Xu J,Wang M, Xiang Y, Hu X. Quality of life for people with intellectual disabilities in China: A cross-culture perspectives study.J Intellect Disabil Res 2005;49(I0):745-9.

12. Lachapelle Y,Wehmeyer ML, Haelewyck MC, Courbois Y, Keith KD, Schalock R,Verdugo MA,Walsh PN. The relationship between quality of life and self-determination: An international study.J Intellect Disabil Res 2005;49(Pt 10):740-4.

13. Duvdevany I, Ben-Zur H,Ambar A. Self-determination and mental retardation: Is there an association with living arrangement and lifestyle satisfaction? Ment Retard 2002;40(5):379-89.

I4. van Hooren RH,Widdershoven GAM, van den Borne HW, Curfs LMG. Autonomy and intellectual disability: The case of prevention of obesity in Prader-Willi syndrome.J Intellect Disabil Res 2002;46(Pt 7):560-8.

15. Hatton C, Emerson E, Robertson J, Gregory N, Kessissoglou S, Walsh PN.The Resident Choice Scale: A measure to assess opportunities for self-determination in residential settings.J Intellect Disabil Res 2004;48 (Pt 2):103-13.

16. Emerson E, Bromley J.The form and function of challenging behaviours. J Intellect Disabil Res 1995;39 ( Pt 5):388-98.

17.Allen B, Katz G, Rangel Euduve G, Lazcano Ponce E. “CADI-Un modelo educativo para adolescentes $y$ adultos mexicanos con discapacidad intelectual: su contribución a la inclusión social con calidad de vida." Conferencia Magistral. $4^{\circ}$ Simposio Internacional:Avances recientes en educación. Acambay, Estado de México, I4-I5 March, 2007. 18.Allen B, Katz G, Rangel-Eudave G, Lazcano-Ponce E."Evaluation of the quality of service delivery by the Integral Training and Development Center (CADI) in Mexico City, Mexico: quality of life and independent living." International Summit for the Alliance on Social Inclusion-AAMR Québec. Oral presentation. Montreal, Canada, 3-5 May, 2006.

19. Strauss A, Corbin J. Basics of Qualitative Research: Grounded Theory Procedures and Techniques. Thousand Oaks, CA: Sage, 1990.

20. Bernard HR. Social research methods: Qualitative and quantitative approaches. Thousand Oaks, CA: Sage, 2000.

21. Bramston P, Chipuer H, Pretty G. Conceptual principles of quality of life:An empirical exploration.J Intellect Disabil Res 2005;49(Pt 10):728-33. 22. Bertelli M, Brown I. Quality of life for people with intellectual disabilities. Current Opinion in Psychiatry 2006; 19:(5)508-513.

23. van Hooren RH,Widdershoven GA, Candel MJ, van den Borne BW, Curfs LM. Between control and freedom in the care for persons with Prader-Willi syndrome: An analysis of preferred interventions by caregivers. Patient Educ Couns 2006;63(I-2):223-3I.

24. van Hooren RH,Widdershoven GA, van der Bruggen $H$, van den Borne HW, Curfs LM.Values in the care for young persons with PraderWilli syndrome: Creating a meaningful life together. Child Care Health Dev. 2005;3I(3):309-19.

25. Whitehead T. Autonomy and competency-- Self-determination in the lives of adults with developmental disabilities. Bioethics Forum 1999;15(2):19-30.

26. Stancliffe RJ. Living with support in the community: Predictors of choice and self-determination. Ment Retard Dev Disabil Res Rev 2001;7(2):91-8.

27. Gutiérrez-Aguilar R. Desandar el laberinto: Introspección en la feminidad contemporánea. La Paz, Bolivia: Muela del Diablo Editores, 1999. 28. Duvdevany I,Arar E. Leisure activities, friendships, and quality of life of persons with intellectual disability: Foster homes vs community residential settings. Int J Rehabil Res 2004 Dec;27(4):289-96.

29. Eastgate G. Sex, consent and intellectual disability. Aust Fam Physician 2005;34(3):163-6.

30. Servais L. Sexual health care in persons with intellectual disabilities. Ment Retard Dev Disabil Res Rev 2006; I2(I):48-56.

3I. Robertson J, Emerson E, Hatton C, Gregory N, Kessissoglou S, Hallam A,Walsh PN. Environmental opportunities and supports for exercising self-determination in community-based residential settings. Res Dev Disabil 200I;22(6):487-502. 